\title{
Moderate spectral resolution solar irradiance measurements, aerosol optical depth, and solar transmission from 360 to 1070 nm using the refurbished Rotating Shadowband Spectroradiometer (RSS)
}

5

\author{
Joseph J. Michalsky ${ }^{1,2}$ and Peter W. Kiedron ${ }^{2}$ \\ ${ }^{1}$ NOAA Earth System Research Laboratory, Boulder, Colorado, 80305, USA \\ ${ }^{2}$ Cooperative Institute for Research in Environmental Sciences, University of Colorado, Boulder, 80309, USA
}

Correspondence to: Joseph J. Michalsky (joseph.michalsky@noaa.gov)

\begin{abstract}
This paper reports on a third generation rotating shadowband spectroradiometer (RSS) used to measure global and diffuse horizontal plus direct normal irradiances and transmissions at 1002 wavelengths between 360 and $1070 \mathrm{~nm}$. The prism-dispersed spectral data are from the ARM Southern Great Plains site in north central Oklahoma (36.605 N, 97.486 W) and cover dates between August 2009 and February 2014. The refurbished RSS isolates the

15 detector in a vacuum chamber with pressures near $10^{-7}$ torr. This prevents the deposition of outgassed vapors from the interior of the spectrometer shell on the cooled detector that affected the operation of the first commercial RSS. Methods for (1) ensuring the correct wavelength registration of the data and (2) deriving extraterrestrial responses over the entire spectrum, including throughout strong water vapor and oxygen bands, are described. The resulting data produced are archived as ARM data records and include cloud-screened aerosol optical depths as well as spectral irradiances and solar transmissions for all three solar components.
\end{abstract}

\section{Introduction}

25 The rotating shadowband spectroradiometer was developed to provide spectrally-resolved measurements of the shortwave spectrum for the Atmospheric Radiation Measurement (ARM) program (Stokes and Schwartz, 1994). The instrument measures global and diffuse horizontal irradiance by alternately shading and unshading the diffuser that serves as the $2 \pi$ steradian input optic to the spectrometer; it then calculates direct normal irradiance from these and a laboratory-measured, spectrally-dependent correction for the angular (cosine) response of the receiver.

To date RSS data have been used in several studies, for example; to derive water vapor by fitting a model to direct spectral irradiance data (Kiedron et al., 2001), to derive water vapor in overcast conditions by using diffuse spectral irradiance (Kiedron et al., 2003), to measure the photon pathlength to help decipher the structure of clouds over the ARM site in northern Oklahoma (Min and Harrison, 2009; Min et al., 2001; Min and Clothiaux, 2003), and to better understand aerosol retrievals (Gianelli et al., 2005) using the expanded wavelength data set.

The early versions of the visible-wavelengths RSS are briefly described in Harrison et al. (1999). Only the key features will be highlighted in this paper followed by a description of the fix implemented to eliminate the problem of the contamination of the detector surface that is present in the first commercial, i.e., second generation, RSS. The method developed to ensure correct wavelength assignments to the spectra is described and illustrated. Our approach to estimating the top-of-atmosphere responses of the instrument in the water vapor and oxygen bands, where traditional Langley analysis cannot be used, is described and demonstrated.

\section{Fundamental Instrument Details}

Since the basics of the rotating shadowband spectroradiometer (RSS) that operates in the visible wavelengths and the ultraviolet version (UV-RSS) have been described in previous papers (Harrison et al., 1999; Kiedron et al., 2002, respectively), only a brief description of the key features of the RSS will be provided in this paper. 
50 The spectrograph contains two prisms in tandem after the collimating lens to achieve a moderate spectral resolution, which has a FWHM (full width at half maximum) of $0.6 \mathrm{~nm}$ near $360 \mathrm{~nm}$ and FWHM of $7 \mathrm{~nm}$ near $1070 \mathrm{~nm}$. The chromatic aberration in this system requires that the detector, positioned after the focusing lens, be tilted to optimize the focus at all wavelengths. The light from the sun and/or sky passes through a diffusing disk that is designed to provide an approximate Lambertian (cosine) response to incoming radiation at all wavelengths. The light from the diffuser enters an integrating cavity that has an exit slit that passes light to the optical train discussed above. The band that shadows the diffuser is positioned below the horizon at the beginning of every cycle where dark and then global horizontal measurements are made; it then moves to three positions near the sun and samples at each of these. Two of these stops are near and on either side of the sun, but do not block it; the mid-stop totally blocks direct sunlight. The sideband measurements are used to calculate a first order correction for excess skylight blocked by the

60 band during the measurement with totally blocked direct sunlight. Using these measurements and pre-deployment, wavelength-dependent cosine response corrections, global and diffuse horizontal and direct normal irradiances can be calculated for 1002 continuous wavelengths.

The inside of the spectrograph is maintained at a temperature near $45^{\circ} \mathrm{C}$, but the detector itself is maintained at a temperature near $20^{\circ} \mathrm{C}$. This provided a detector surface in the original design that was a target for condensates from outgassing vapors from the interior of the spectrograph that caused the responsivity to change over time. In the original commercial instrument, this meant frequent recalibrations to keep up with the changing response of the detector. In this new design the detector is mounted on a copper cold finger and housed in a windowed vacuum chamber that is held at a pressure of around $10^{-7}$ torr, which effectively eliminates the condensation issue (see 70 Figure 1).

\section{Operational Details}

The refurbished RSS was deployed at the ARM site in northern Oklahoma $\left(36.605^{\circ} \mathrm{N}, 97.486^{\circ} \mathrm{W}, 317 \mathrm{~m}\right)$ and

75 began operating on 26 August 2009; the shutter stopped opening on 21 February 2014. Note that between 25 December 2013 and 21 February 2014 shutter operation was intermittent, thus many data were lost during these last three months of operation. The cycle of four irradiance measurements plus one dark measurement was repeated every minute starting at the top of the minute. Exposure times for each measurement were between 0.4 and 4 seconds based on the irradiance level at the start of the cycle. There is a small variation in the sampling time caused

80 by band travel to the sun's position. In the morning the sampling is nearer the top of the minute and somewhat later in the afternoon. The band motor speed is, however, about one revolution per 6 seconds, therefore, the delay in afternoon sampling is less than this.

There were some issues with band alignment, which were detected using a Fast-Fourier Transform (FFT) procedure, that resulted in data being flagged as suspect. Furthermore, the initial five weeks of data showed suspicious wavelength dependencies in the AODs, perhaps caused by a few, poorly determined extraterrestrial response retrievals at the beginning of the measurement set, and, therefore, we suggest that data taken before 1 October 2009 have a large uncertainty; however, irradiances and transmissions for the first five weeks were not removed from the database and should be used with caution.

\subsection{Wavelength Registration}

Although the spectrograph is rigidly secured to the frame that stabilizes it, slight changes in pixel alignment (note that pixels are about $14 \mu \mathrm{m}$ wide) can occur due to slight mechanical or optical shifts associated with the thermal

95 environment or external movements of the instrument, for example, caused by high wind speeds. During the four and a half years of measurements, pixel shifts to shorter and longer wavelengths of up to four pixels in either direction were noted. Since we wish to use the same wavelength coverage for the entire period, we were left with 1002 pixels whose response was deemed satisfactory over the complete period of record. This included wavelengths between 360.4 and $1070.1 \mathrm{~nm}$.

To ensure proper wavelength registration, nine global horizontal spectra, typically taken near solar noon each day, were averaged. This average was compared to the global horizontal spectrum used as a standard for all days where the wavelength registration was carefully determined using pencil lamp spectra and solar absorption features. Both of these global horizontal spectra were fitted with low order spline fits that were subtracted from each to enhance the 
105 major absorption features. A cross-correlation was performed between these two residual spectra at tenth-pixel increments until the correlation between spectra reached a maximum. Only wavelengths less that $672 \mathrm{~nm}$ were used for the spline fit and cross correlation because these absorption features were mostly in the solar spectrum, and the terrestrial spectrum only has weak absorption lines in this part of the spectrum. We did not want to cross-correlate terrestrial features on different days where the water vapor content may have influenced the cross correlation. The

110 spectra for that day were then shifted by the amount of pixel offset from the 'standard' spectrum. This spectral shift process is illustrated in Figure 2. Note that the blue-colored spectrum on the left is displaced slightly shortward relative to the extraterrestrial and standard spectrum (designated 'tothor' in the figure). The shift in the left panel of Figure 2 was two pixels. The process described above was then perform and the blue-colored spectrum replotted on the right. On the right all three spectra are well aligned. This shift for the spectra is performed only once each day

115 since the shifts that are observed undergo slow, subtle changes.

\subsection{Estimation of Extraterrestrial Response in Strong Terrestrial Absorption Bands}

120 It is our goal to generate a continuous spectrum of the transmission over the entire wavelength span of the RSS. Transmissions are calculated by dividing the measured response of the RSS by the response at the top of the atmosphere (TOA) adjusted for solar distance. Many portions of the solar spectrum can use Langley analysis to estimate the TOA response. However, measurements in the strong bands of $\mathrm{H}_{2} \mathrm{O}$ and $\mathrm{O}_{2}$ are not well-suited for Langley analysis, since a linear curve of growth is not expected for these strong molecular bands, and, consequently,

125 the extrapolation to zero airmass underestimates the TOA at these wavelengths.

Reagan et al. (1987) and Bruegge et al. (1992) were among the first to perform a modified Langley analysis to derive water vapor, but as Michalsky et al. (1995) pointed out this method depends on stable water vapor over the measurement period used for the modified Langley, which is seldom the case. Consequently, a very large number of

130 modified Langleys, which require a very long period of time and a stable instrument over that time, are typically required to even approach the accuracy in extraterrestrial response that a standard Langley analysis can achieve when working outside strong molecular bands.

In this paper we used an interpolation over two strong $\mathrm{O}_{2}$ bands and three strong $\mathrm{H}_{2} \mathrm{O}$ bands. The function used for the interpolation is given by equation (1)

$$
V_{0}^{\prime}(\lambda)=R(\lambda) \cdot \operatorname{ET}(\lambda)\left[\frac{\frac{V_{0}^{\prime}\left(\lambda_{2}\right)}{R\left(\lambda_{2}\right) \cdot E T\left(\lambda_{2}\right)}-\frac{V_{0}^{\prime}\left(\lambda_{1}\right)}{R\left(\lambda_{1}\right) \cdot E T\left(\lambda_{1}\right)}}{\lambda_{2}-\lambda_{2}}\left(\lambda-\lambda_{1}\right)+\frac{V_{0}^{\prime}\left(\lambda_{1}\right)}{R\left(\lambda_{1}\right) \cdot E T\left(\lambda_{1}\right)}\right]
$$

where $V_{0}^{\prime}(\lambda)$ is the estimated extraterrestrial response in the molecular band at wavelength $\lambda$; subscripts 1 and 2 of $\lambda$ indicate $V_{0}(\lambda)$ 's determined from standard Langley analysis, RSS responses $R(\lambda)$, and extraterrestrial irradiances $E T(\lambda)$ at wavelengths $\lambda_{1,2}$ just before and just after each of these five molecular bands, respectively.

Extraterrestrial (ET) solar irradiance at RSS spectral resolution was determined using the slit function of the RSS applied to the high spectral resolution ET spectrum of Kurucz (http://rtweb.aer.com/solar_frame.html), but scaled to the low-resolution, but well-determined absolute ET spectrum of Gueymard (2006). Figure 3 displays the

145 extraterrestrial spectrum at RSS spectral resolution with higher spectral resolution in the short wavelengths and lower resolution at long wavelengths as expected for a prism spectrograph.

The response function $R(\lambda)$ in equation (1) was determined by dividing the calibration lamp output in W/m² $-\mathrm{nm}$ by the RSS calibration function in $\mathrm{W} / \mathrm{m}^{2}$-nm per count. Figure 4 is a plot of the RSS responsivity. We only require

150 relative response for the interpolations using equation (1).

Figure 5 illustrates the $\mathrm{V}_{0}$ interpolation using equation (1) when implemented for five strong molecular bands within the wavelength span of the RSS. The black line is the extraterrestrial spectrum (y-axis label); the magenta line is the scaled, uncalibrated total horizontal irradiance in counts that is our standard for wavelength registration as discussed previously; the solid green line is a scaled uncalibrated retrieval of the RSS extraterrestrial response from a morning 

$\mathrm{H}_{2} \mathrm{O}$. The $\mathrm{H}_{\alpha}$ and $\mathrm{Na}$ lines that are in the extraterrestrial solar spectrum are identified and appear in all three spectra. The interpolations of the extraterrestrial spectrum over the $\mathrm{O}_{2}$ and $\mathrm{H}_{2} \mathrm{O}$ bands seem reasonable and will be used for extraterrestrial responses as these are expected to be plausible estimates. With these estimates we can now calculate the continuous global and diffuse horizontal and direct normal solar spectral transmissions from 360 to $1070 \mathrm{~nm}$.

\section{Solar Transmission Calculations and Examples}

As explained in the previous paragraphs, now that we have estimates for the extraterrestrial response over the entire RSS spectral response wavelength span, we can calculate transmissions in all three components; global and diffuse horizontal and direct normal. Figure 6 is a plot of transmission near solar noon on 27 October 2009, which was clear from horizon to horizon at this time of day. Compared to the structure at short wavelengths in the extraterrestrial spectral irradiance (see Figure 3), the transmissions are extremely monotonic up to $550 \mathrm{~nm}$ and mostly the result of Rayleigh scattering and aerosol extinction, although Rayleigh scattering and aerosol extinction contribute

170 throughout the entire RSS spectral range with decreasing contributions at the longer wavelengths. Both Rayleigh scattering $\left(\lambda^{-4}\right)$ and aerosol scattering (often $\sim \lambda^{-1.3}$ ) are wavelength dependent with the contributions falling off with increasing wavelength. This explains the lower transmission at the shortest wavelengths for the dni and the higher transmission at the shortest wavelengths for the dhi. There is only a minor indication of imperfect wavelength registration (smaller than $0.1 \mathrm{~nm}$ ) that gives rise to small residuals of the very strong $\mathrm{H}$ and $\mathrm{K}$ lines of singly ionized calcium (CaII) at 393.4 and $396.9 \mathrm{~nm}$ in the solar spectrum. The major absorption bands of $\mathrm{O}_{2}$ near 690 and $760 \mathrm{~nm}$ and $\mathrm{H}_{2} \mathrm{O}$ near 725, 820, and $940 \mathrm{~nm}$, as noted in Figure 5, can be clearly identified. Much less obvious are the $\mathrm{O}_{2}-\mathrm{O}_{2}$ bands near 477,577 , and $630 \mathrm{~nm}$, although the latter two bands are near a weak $\mathrm{H}_{2} \mathrm{O}$ water band $(577 \mathrm{~nm})$ or near weak $\mathrm{H}_{2} \mathrm{O}$ and $\mathrm{O}_{2}$ bands $(630 \mathrm{~nm})$ that complicate their identification and separation. The slight falloff in dni at the longest wavelengths near the end of the RSS spectrum is mostly the result of another weak $\mathrm{O}_{2}-\mathrm{O}_{2}$ band centered near $1065 \mathrm{~nm}$. Somewhat less discernible is the broad Chappuis $\mathrm{O}_{3}$ band center roughly near $610 \mathrm{~nm}$. Although no retrievals will be performed in this paper, the transmission in the $\mathrm{H}_{2} \mathrm{O}$ bands can be used to estimate column $\mathrm{H}_{2} \mathrm{O}$ by running a suitable radiative transfer code at the RSS spectral resolution in transmission until an optimum match to the three $\mathrm{H}_{2} \mathrm{O}$ bands is attained. Less obvious and more uncertain is the use of the Chappuis band transmission to estimate column $\mathrm{O}_{3}$. Notice that the dni transmission on this clear day is about $95 \%$ at wavelengths above $1000 \mathrm{~nm}$ 185 and slightly higher for ghi.

Figure 7 is interesting in that this is a plot with a clear path to the sun with ghi exceeding $100 \%$ transmission at wavelengths greater than about $650 \mathrm{~nm}$ (except, of course, for the strong absorption features). dni is slightly lower than it was in Figure 6 and dhi is considerably higher.

We can understand how transmissions above $100 \%$ are possible if we consider Figure 8, where the vertical red line marks the time of day that the spectra in Figure 7 were measured. dni appears unaffected at this point in time, but a short time later clouds are clearly moving in front of the sun. Because clouds are encroaching, diffuse is enhanced by direct sunlight scattering from them, which causes enhancements in the ghi. This is a well-recognized effect in

195 broadband solar measurements that is discussed, for example, in Vignola et al. (2020) (see p. 21 and Figure 2.14 in that reference). Additionally, Figure 7 illustrates the wavelengths where the apparent transmission exceeds $100 \%$.

Figure 9 is a plot of the transmission through a totally overcast sky on 25 October 2009 at the ARM site in northern Oklahoma. That the sky was totally cloudy was confirmed using the total sky imager collocated at the site. Note that 200 the dni is zero for all wavelengths and the ghi is hidden by the dhi plot that should and does exactly overlay it for overcast conditions. The spectrum outside molecular absorption bands indicates a slight monotonic increase in transmission with wavelength. Although there is a slight decrease in transmission centered near $600 \mathrm{~nm}$ that appears to counter this suggestion that the continuum monotonically increases with wavelength, this is the broad, weak Chappuis $\mathrm{O}_{3}$ band. The large $\mathrm{H}_{2} \mathrm{O}$ and $\mathrm{O}_{2}$ bands identified in Figure 5 are labeled left to right starting around 690

$205 \mathrm{~nm}$. Much weaker absorption bands below $690 \mathrm{~nm}$ can be identified. Using Sierk et al. (2004) allows us to identify the three weak bands between 550 and $690 \mathrm{~nm}$ with the molecules causing the absorption features. The very weak depression around $477 \mathrm{~nm}$ is caused by $\mathrm{O}_{2}-\mathrm{O}_{2}\left(\mathrm{aka}, \mathrm{O}_{4}\right)$ absorption (Michalsky et al. 1999). The feature labeled $\mathrm{H}_{2} \mathrm{O}$ ? is likely a water vapor band that is in the HITRAN (2012) database. The Ca II H and K lines short of $400 \mathrm{~nm}$ appear as small residuals because of slightly imperfect wavelength registration, (smaller than $0.1 \mathrm{~nm}$ ) but this is a 210 minor issue since these are the two strongest lines in the extraterrestrial spectrum. The downturn at the longest wavelengths is absorption in the $\mathrm{O}_{4}$ band that is centered near at $1065 \mathrm{~nm}$ although the wings of a $\mathrm{H}_{2} \mathrm{O}$ bands may 
be influencing this part of the spectrum as well. Figure 10 is a similar plot on 24 October 2009 with slightly higher transmission. This plot shows a more pronounced Chappuis $\mathrm{O}_{3}$ band centered near $600 \mathrm{~nm}$, which is the broad depression in what looks like continuum.

Figure 11 is a spectral irradiance plot from 24 December 2009 for totally overcast skies that has a starkly different appearance than the earlier plots (Figures 9 and 10) for overcast days. On this day at the time of this measurement the radar indicated substantial ice content in the clouds above the site. The attenuation above $1000 \mathrm{~nm}$ is consistent with radiance transmission spectra for ice clouds presented in LeBlanc et al. (2015); for example, compare their Figure 3(b). Consequently, there is the potential to use these spectra to recognize ice phase and, more importantly, retrieve quantitative information on ice content and size. There is clearly an incentive to study this further, although it is beyond the current focus of this paper.

\section{Aerosol Optical Depths}

Since transmissions have been calculated and are available, it should be straightforward to calculate aerosol optical depths (AODs) for the parts of the spectrum that are free of strong $\mathrm{H}_{2} \mathrm{O}$ and $\mathrm{O}_{2}$ absorption bands. Since we have determined estimates for extraterrestrial responses $V_{0}(\lambda)$ 's, and we measure responses at the surface $V(\lambda)$ 's, we can calculate optical depths by solving for $\tau$ in the following

$$
V(\lambda) / V_{0}(\lambda)=e^{-\tau(\lambda) \cdot m}
$$

where $m$ is a known, calculated airmass, $\tau(\lambda)$ is the total optical depth, and $V_{0}(\lambda)$ has been adjusted for the correct solar distance for the time of observation. From the total optical depth $\tau(\lambda)$ we must remove the optical depths associated with Rayleigh scattering and Chappuis band $\mathrm{O}_{3}$ absorption to retrieve estimates for AODs where there are no molecular bands.

Figure 12 is a plot of optical depth versus wavelength at 11:45 local standard time for 25 November 2009 at the ARM site with Rayleigh and ozone optical depth removed. The vertical lines are positioned at the CIMEL sunphotometer wavelengths used by AERONET in this wavelength range (https://aeronet.gsfc.nasa.gov/ (Holben et al., 2001) to measure AOD. All of these appear to be in windows not affected by the strong $\mathrm{O}_{2}$ and $\mathrm{H}_{2} \mathrm{O}$ bands. As

240 an aside, note that if we examine this and any of our similar transmission figures that the weak water band centered near $505 \mathrm{~nm}$ could have a small influence on the AOD assigned to this wavelength even though it has long been a standard wavelength for AOD measurements (WMO/GAW, 2016).

The shorter wavelengths appear noisier because the wavelength alignment is to the nearest 0.1 pixels where the spectral resolution is the highest for this instrument, the signal-to-noise ratio is lowest at these wavelengths, and the extraterrestrial spectrum is inherently more structured at these wavelengths for a prism spectrograph. Figure 13 is a log-log plot of RSS AODs (open circles) versus wavelength for the RSS pixels nearest in wavelength to the AERONET wavelengths. For the $1020 \mathrm{~nm}$ pixel an additional minor correction for water vapor (original marked by ' $\mathrm{X}$ ' in Figure 13), based on the work presented by Smirnov (2004, unpublished), brings the wavelength dependence more in line with the shorter wavelength points. The slope (Angstrom exponent) determined by a linear fit to these RSS data is 0.711 , not uncommon for late autumn aerosols. The filled circles are the nearest in time AERONET data (within 2.5 minutes) for the AERONET wavelengths. Other than the $1020 \mathrm{~nm}$ points, the data are within 0.008 optical depths with similar wavelength dependencies.

\section{Irradiance Calculations}

Just as for the aerosol optical depth calculations, if we are given the transmission, it is straightforward to calculate the spectral irradiance for all three components. All that is required is to use the extraterrestrial (ET) spectral irradiance at the spectral resolution of the RSS (see Figure 3) and adjust for the solar distance at the time of the

260 measurements. Multiplying each component (ghi, dni, and dhi) by this distance-corrected ET spectral irradiance for each of the pixels yields the estimated spectral irradiance for each component at the surface.

Figure 14 is the calculated spectral irradiance for the same day as in Figure 3, namely, 27 October 2009 at the ARM site in northern Oklahoma. Most of the uncertainty associated with irradiance data arises from the uncertainty in the 
265 ET spectral irradiance. Transmission uncertainty is estimated at $1 \%$, but the ET uncertainty is $2 \%$ or higher, as indicated by Gueymard (2018; private communication), depending on what portion of the $360-1070 \mathrm{~nm}$ spectral range is under study. Of course, for cloudy periods the dni will be zero and the dhi and ghi will be the same as can be inferred from Figures 9-11. In Figure 13 note that the ghi is not the sum of dhi and dni because dni is not the direct projected onto a horizontal surface, which would be dni $\cdot \cos (\mathrm{sza})$.

270

\section{Data Availability}

For those interested, the data are freely available and are archived with the ARM program and can be downloaded using https://iop.archive.arm.gov/arm-iop/0pi-data/michalsky/RSS/. Some additional notes on data quality are at 275 ftp://aftp.cmdl.noaa.gov/user/michalsky/ in the folder 'asked_for_stuff'.

\section{Acknowledgments}

The authors are indebted to Jerry Berndt for designing, building, and assembling the vacuum chamber and mount for the refurbished detector and his tenacity in making the system function. Scott Stierle not only developed software to ingest the data and provide a clean documented file for each day of the 4.5 years of RSS data, but helped deploy and performed field repairs during the deployment. Patrick Disterhoft provided laboratory facilities and technical direction in the refurbishment of the RSS. This research was funded by the United States Department of Energy, Office of Science's Atmospheric Radiation Measurement program.

\section{References}

Bruegge, C.J., Conel, J. E., Green, R. O., Margolis, J. S., Holm, R. G., and Toon, G.: Water vapor column abundance retrievals during FIFE, J. Geophys. Res., 97, 18,759-18,768, doi.org/10.1029/92JD01050, 1992.

Gianelli, S. M., Carlson, B. E., and Lacis, A. A.: Aerosol retrievals using rotating shadowband spectroradiometer data, J. Geophys. Res., 110, D05203, doi.org/10.1029/2004JD005329, 2005.

295 Gueymard, Christian A.: Reference solar spectra: Their evolution, standardization issues, and comparison to recent measurements, Advances in Space Research, 37, 323-340, doi.org/10.1016/j.asr.2005.03.104, 2006.

Gueymard, Christian A.: Revised composite extraterrestrial spectrum based on recent solar irradiance observations, Solar Energy, 169, 434-440, doi.org/10.1016/j.solener.2018.04.067, 2018.

Harrison, L., Beauharnois, M., Berndt, J., Kiedron, P., Michalsky, J., and Min, Q-L.: The Rotating Shadowband Spectroradiometer (RSS) at SGP, Geophys. Res. Lett., 26, 1715-1718, doi.org/10.1029/1999GL900328, 1999.

The HITRAN Database. Atomic and Molecular Physics Division, Harvard-Smithsonian Center for Astrophysics. Retrieved August 8, 2012. HITRAN is a compilation of spectroscopic parameters that a variety of computer codes use to predict and simulate the transmission and emission of light in the atmosphere, https://hitran.org/about/, 2012.

Holben, B.N., Tanre, D., Smirnov, A., Eck, T. F., Slutsker, I., Abuhassan, N., Newcomb, W. W., Schafer, J., Chatenet, B., Lavenue, F., Kaufman, Y.J., Vande Castle, J., Setzer, A., Markham, B., Clark, D., Frouin, R.,

310 Halthore, R., Karnieli, A., O'Neill, N. T., Pietras, C., Pinker, R. T., Voss, K., and Zibordi, G.: An emerging groundbased aerosol climatology: Aerosol Optical Depth from AERONET, J. Geophys. Res., 106, 12067-12097, doi.org/10.1029/2001JD900014, 2001.

315 Kiedron, P., Michalsky, J., Schmid, B., Slater, D., Berndt, J., Harrison, L., Racette, P., Westwater, Spectroradiometer, J. Geophys. Res., 106, 24007-24016. doi.org/10.1029/2000JD000130, 2001. 

rotating shadowband spectroradiometer (UV-RSS), Proc. SPIE 4482, Ultraviolet Ground- and Space-based Measurements, Models, and Effects, doi.org/10.1117/12.452925, 2002.

Kiedron, P., Berndt, J., Michalsky, J., and Harrison, L.: Column water vapor from diffuse irradiance, Geophys. Res. Lett., 30, 1565, doi.org/10.1029/2003GL016874, 2003.

LeBlanc, S. E., Pilewskie, P., Schmidt, K. S., and Coddington O.: A spectral method for discriminating thermodynamic phase and retrieving cloud optical thickness and effective radius using transmitted solar radiance spectra, Atmos. Meas. Tech., 8, 1361-1383, doi.org/10.5194/amt-8-1361-2015, 2015.

Michalsky, J.J., Liljegren, J. C., and Harrison, L. C.:A comparison of sun photometer derivations of total column water vapor and ozone to standard measures of same at the Southern Great Plains atmospheric radiation measurement site, J. Geophys. Res., 100, 25,995-26,003, doi.org/10.1029/95JD02706, 1995.

335 Michalsky, J., Beauharnois, M., Berndt, J., Harrison, L., Kiedron, P., and Q. Min, Q.: $\mathrm{O}_{2}-\mathrm{O}_{2}$ absorption band identification based on optical depth spectra of the visible and near-infrared, Geophys. Res. Lett. 26, 1581-1584, doi.org/10.1029/1999GL900267, 1999.

Min, Q.-L., and Harrison, L. C.: Joint statistics of photon path length and cloud optical depth, Geophys. Res. Lett., 26, 1425-1428, doi.org/10.1029/1999GL900246, 1999.

Min, Q.-L., Harrison, L. C., and Clothiaux, E.: Joint statistics of photon pathlength and cloud optical depth: Case studies, J. Geophys. Res., 106, 7375-7386, doi.org/10.1029/2000JD900490, 2001.

Min, Q., and Clothiaux, E. E., Photon path length distributions inferred from rotating shadowband spectrometer measurements at the Atmospheric Radiation Measurements Program Southern Great Plains site, J. Geophys. Res., 108, 4465-4474, http://doi.org/10.1029/2002JD002963, 2003.

Reagan, J. A., Thome, K., Herman, B., and Gall, R.: Water vapor measurements in the 0.94 micron absorption band: Calibration, measurements and data applications, Proc. Int. Geosci. Remote Sens. Symp., IEEE 87CH2434-9, 63-67, https://arizona.pure.elsevier.com/en/publications/water-vapor-measurements-in-the-0-94-micron-absorption-bandcalib, 1987.

Sierk, B., Solomon, S., Daniel, J. S., Portmann, R. W., Gutman, S. I., Langford, A. O., Eubank, C. S., Dutton, E. G., and Holub, K. H.: Field measurements of water vapor continuum absorption in the visible and near-infrared, J.

355 Geophys. Res., 109, D08307, doi.org/10.1029/2003JD003586, 2004.

Smirnov, A, Holben, B. N., Lyapustin A., Slutsker, I., and Eck, T. F.: AERONET processing algorithms refinement, AERONET 2004 Workshop, 10-14 May 2004, El Arenosillo, Spain, 2004.

360 Stokes, G. M., and Schwartz, S. E.: The Atmospheric Radiation Measurement (ARM) Program: Programmatic background and design of the cloud and radiation test bed, Bull. Amer. Meteor. Soc., 75, 1201-1221, https://doi.org/10.1175/1520-0477(1994)075<1201:TARMPP>2.0.CO\%3B2, 1994.

365 Florida, doi.org/10.1201/b22306, 2020.

WMO/GAW: Aerosol Measurement Procedures, Guidelines and Recommendations. World Meteorological Organization (WMO-No. 1177), Global Atmospheric Watch (GAW Report No. 227), 
https://doi.org/10.5194/amt-2021-162

Preprint. Discussion started: 23 June 2021

(c) Author(s) 2021. CC BY 4.0 License.
Atmospheric Measurement Techniques

Discussions
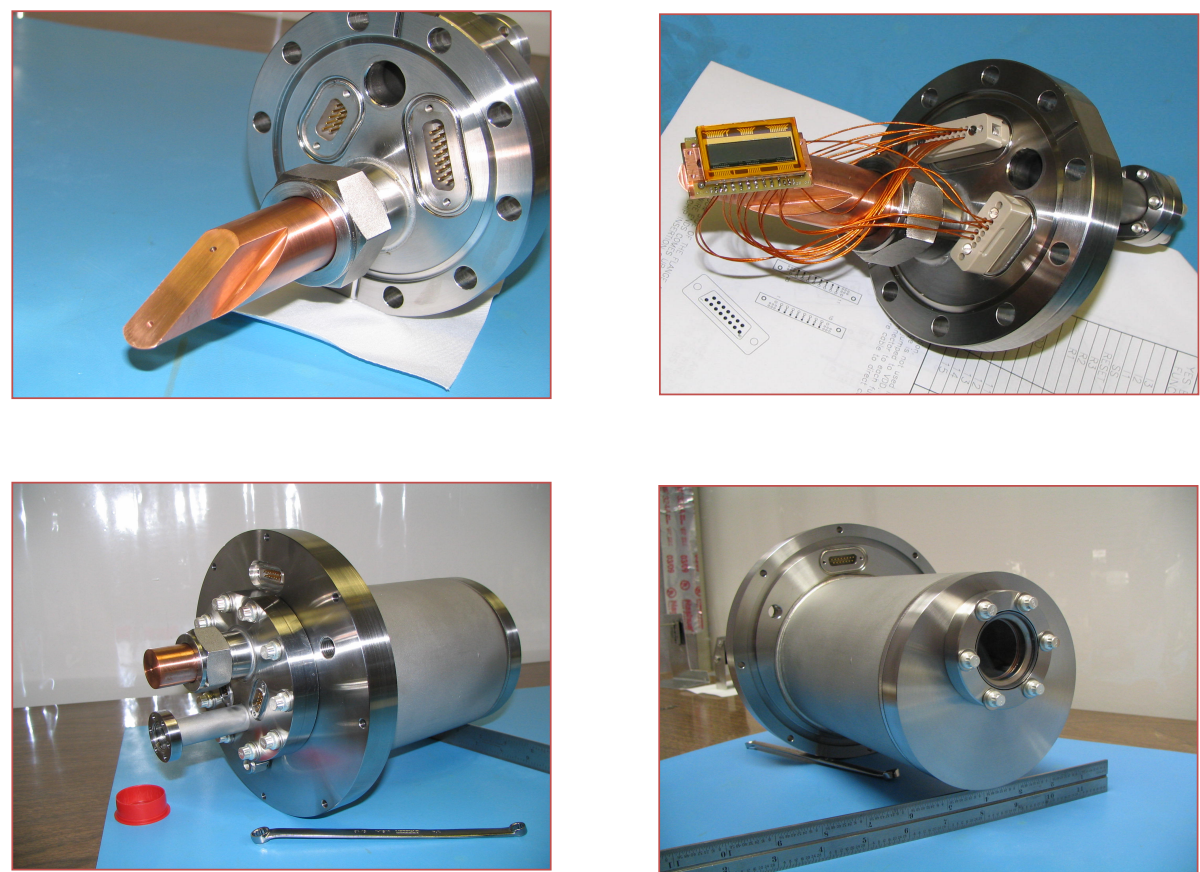

Figure 1: Top left is the cold finger that is held at $20^{\circ} \mathrm{C}$. Top right is the CCD detector that mounts on the copper cold finger. Bottom left and right are the back and front of the assembled housing. The CCD detector is behind the window. 
https://doi.org/10.5194/amt-2021-162

Preprint. Discussion started: 23 June 2021

(c) Author(s) 2021. CC BY 4.0 License.

Before Shift

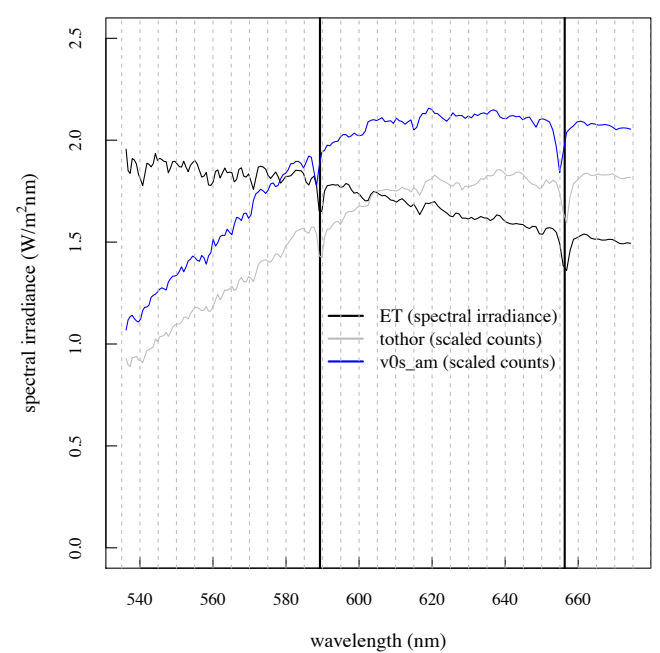

After Shift

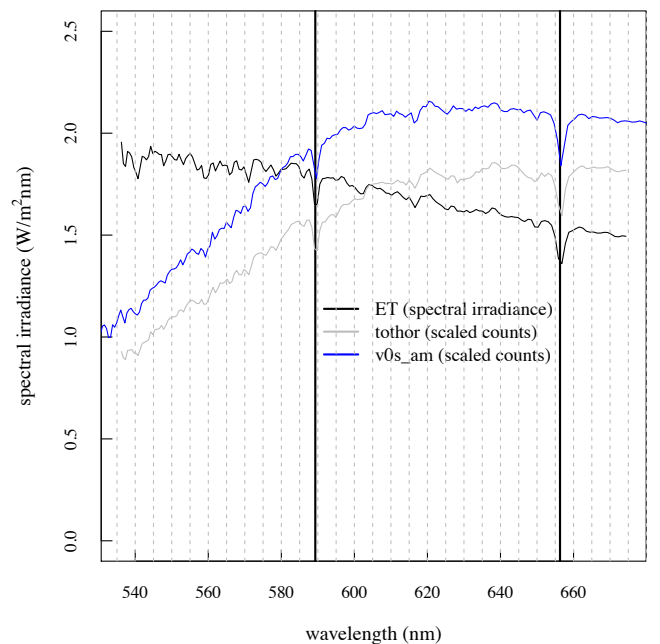

Figure 2: The average of nine spectra near solar noon appear as the blue line; the extraterrestrial spectrum at RSS resolution is the black line, and the gray line is the carefully determined spectrum used as the standard total horizontal spectrum that is compare to all RSS data. The blue spectrum in the left panel is shifted shortward by two pixels and the right panel shows the shift-corrected spectrum. The two absorption lines are in the solar spectrum since they also appear in the ET spectrum; these are the sodium doublet $589.0 / 589.6 \mathrm{~nm}$ and the hydrogen alpha line $656.3 \mathrm{~nm}$. 
https://doi.org/10.5194/amt-2021-162

Preprint. Discussion started: 23 June 2021

(c) Author(s) 2021. CC BY 4.0 License.

ET Spectrum at RSS Resolution

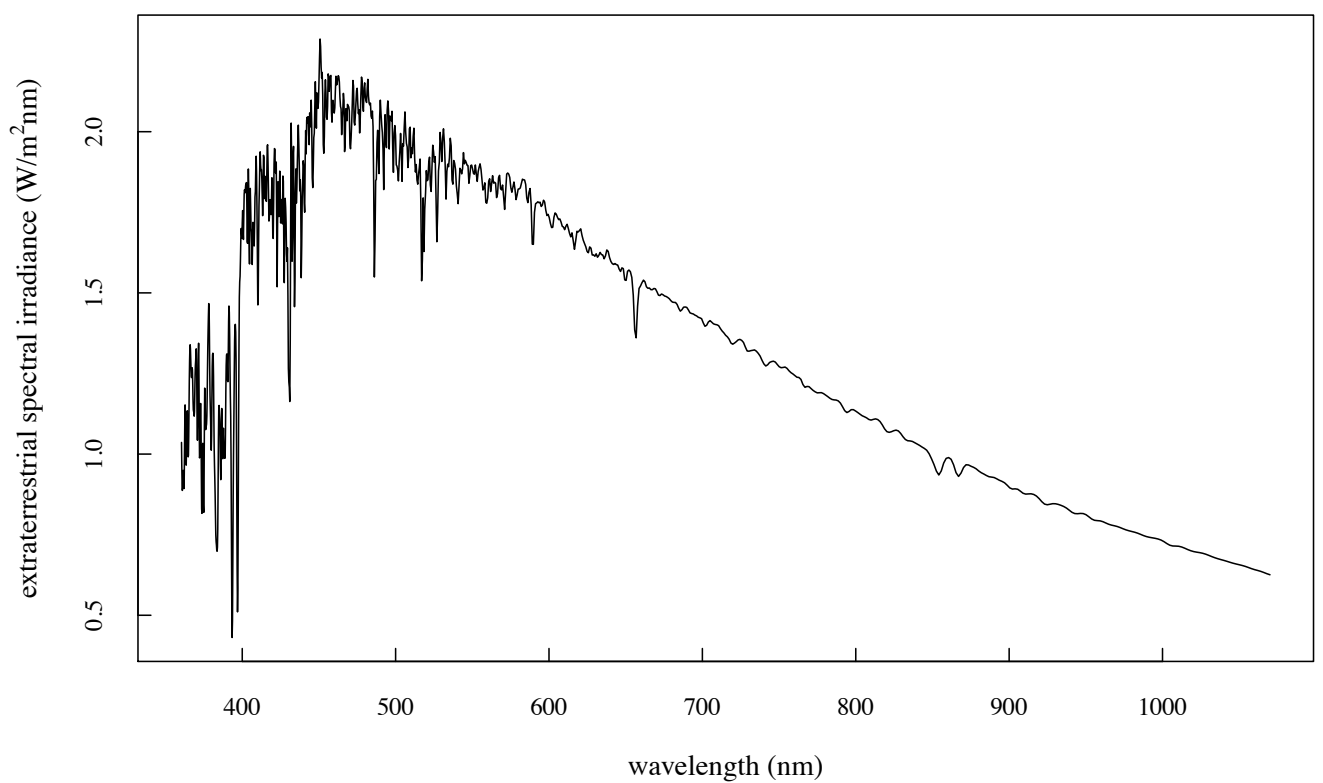

385 Figure 3: Extraterrestrial solar spectrum used for this paper using RSS slit function applied to Kurucz high-resolution calculated ET solar spectrum, then scaled to the Gueymard low resolution ET solar spectrum. 
https://doi.org/10.5194/amt-2021-162

Preprint. Discussion started: 23 June 2021

(c) Author(s) 2021. CC BY 4.0 License.

Atmospheric Measurement

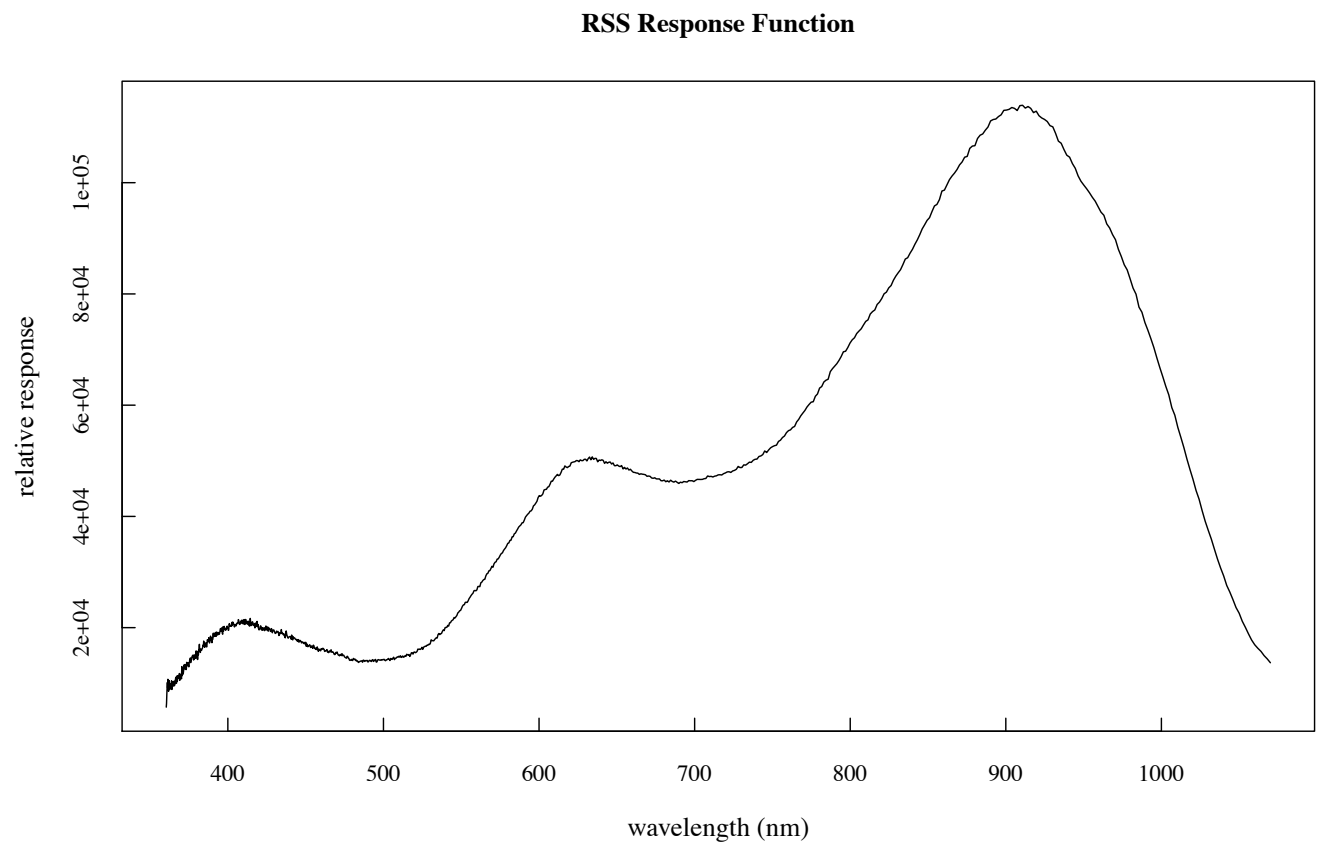

Figure 4: Measured relative response of the RSS that is needed for the interpolation scheme represented by equation (1). 
https://doi.org/10.5194/amt-2021-162

Preprint. Discussion started: 23 June 2021

(c) Author(s) 2021. CC BY 4.0 License.

Atmospheric

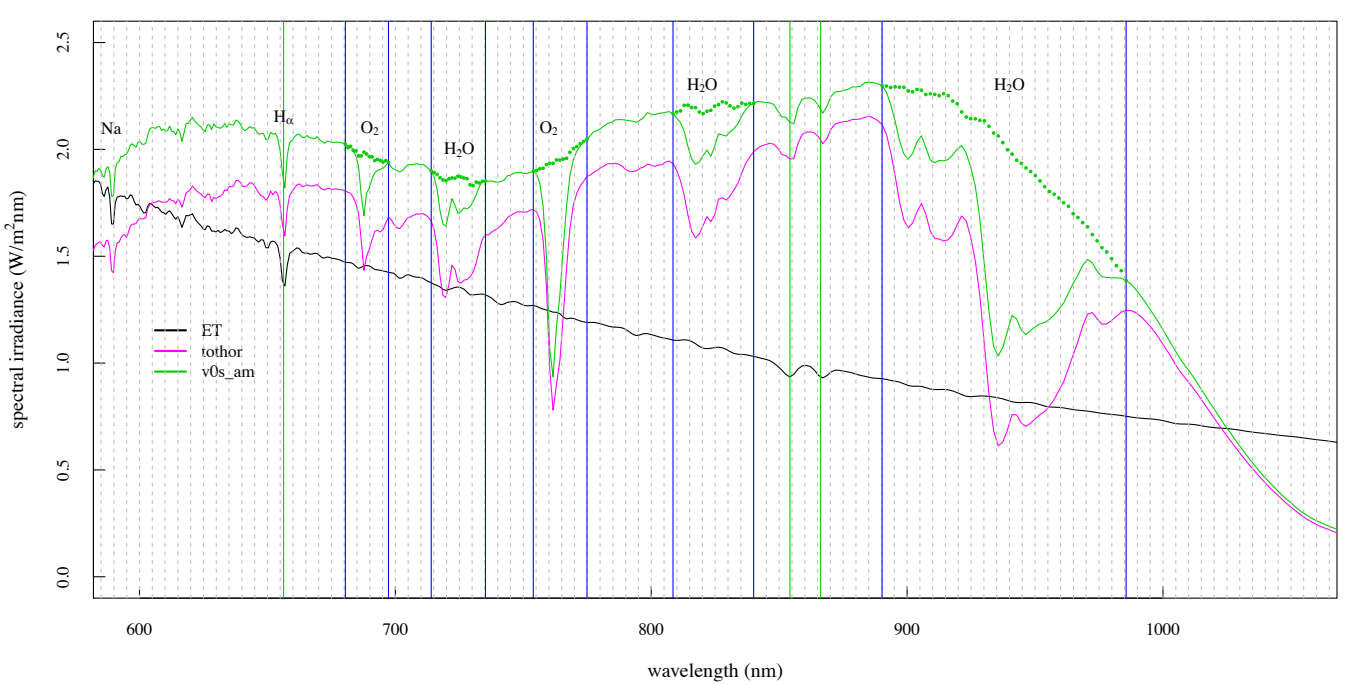

Figure 5: Illustration of the v0 interpolation over strong $\mathrm{O}_{2}$ and $\mathrm{H}_{2} \mathrm{O}$ molecular bands using equation (1) (green dots are interpolated points). Black "ET" line is the extraterrestrial irradiance (y-axis label) for mean distance to the Sun. 
https://doi.org/10.5194/amt-2021-162

Preprint. Discussion started: 23 June 2021

(c) Author(s) 2021. CC BY 4.0 License.

Atmospheric

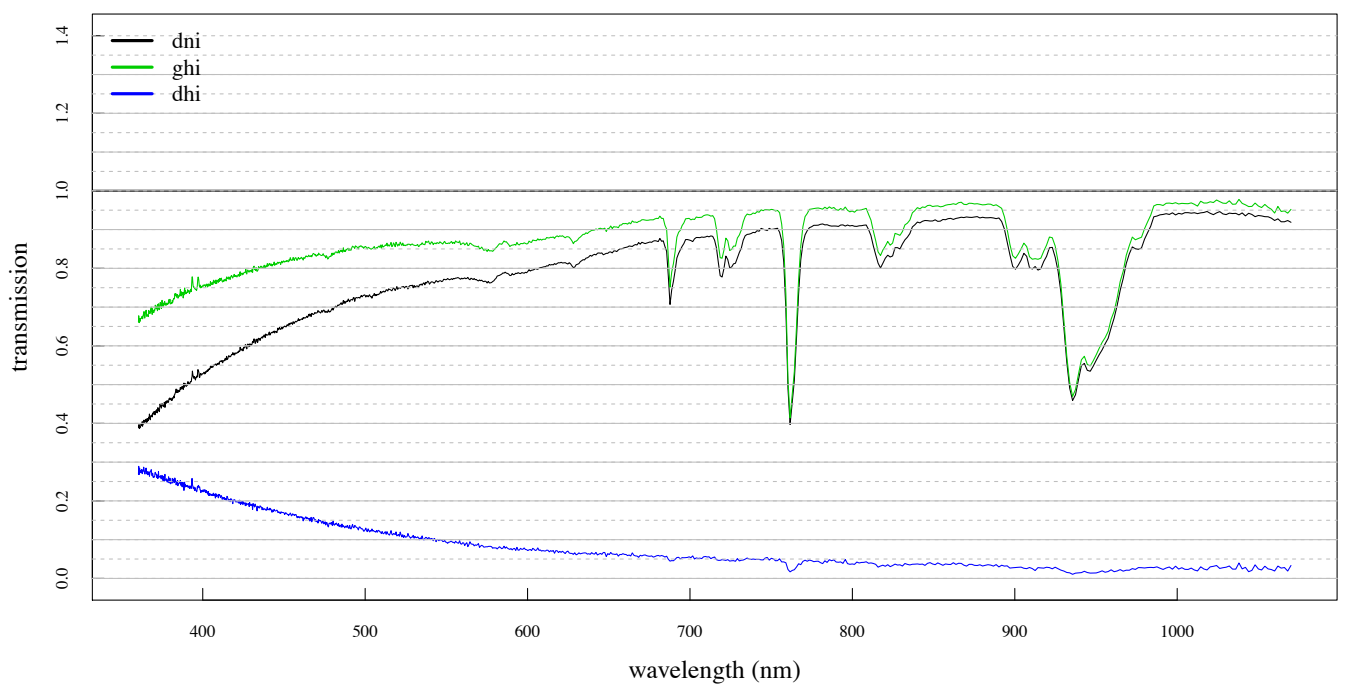

Figure 6: Transmission of global and diffuse horizontal (ghi, dhi) and direct normal (dni) irradiance on a clear day 27 October 2009 at the ARM site in northern Oklahoma. Note that both dni and the horizontal component of dni, which is dni * cos(solar-zenith angle), would have the same transmission profile. Note, also, that the dni and dhi transmissions sum to the ghi transmission. 
https://doi.org/10.5194/amt-2021-162

Atmospheric

Preprint. Discussion started: 23 June 2021

(c) Author(s) 2021. CC BY 4.0 License.

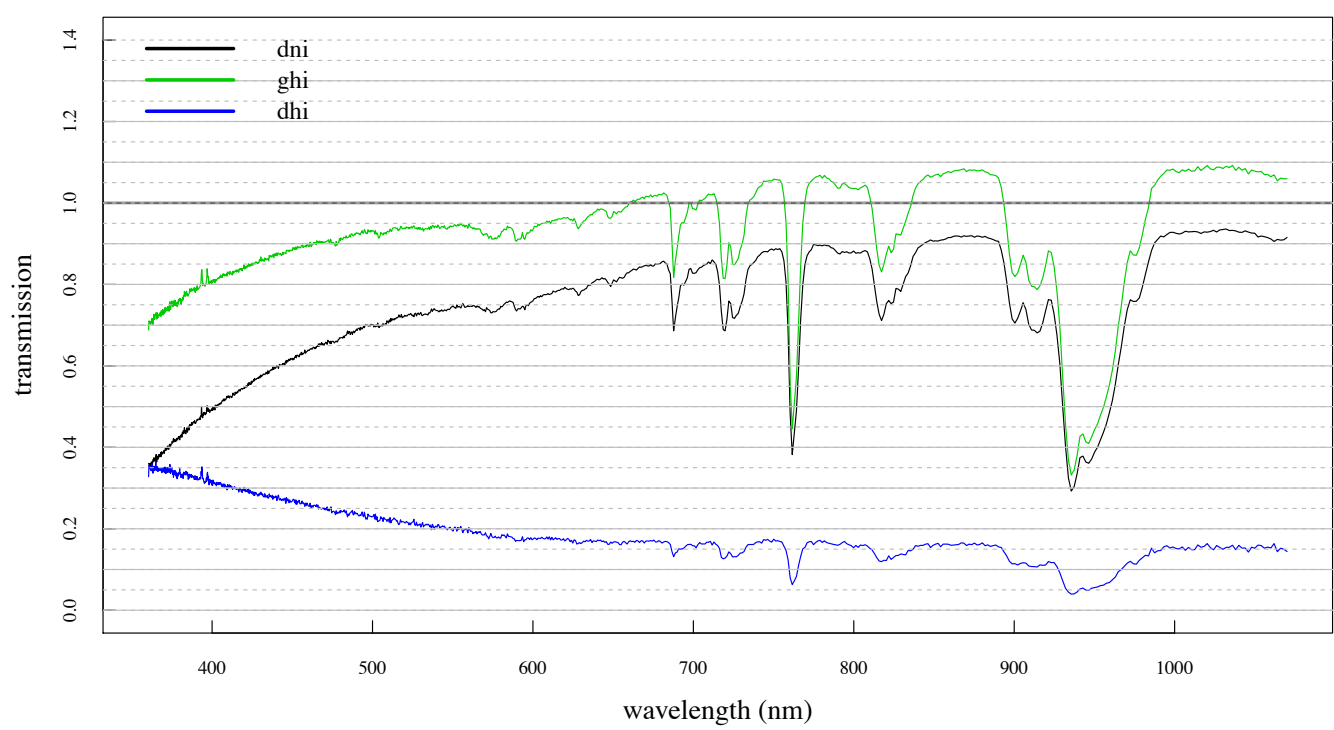

$405 \quad$ Figure 7: RSS spectra for an instance where there is a clear path to the sun on a partly cloudy day. Note that ghi exceeds $100 \%$ transmission at many of the longer wavelengths. 


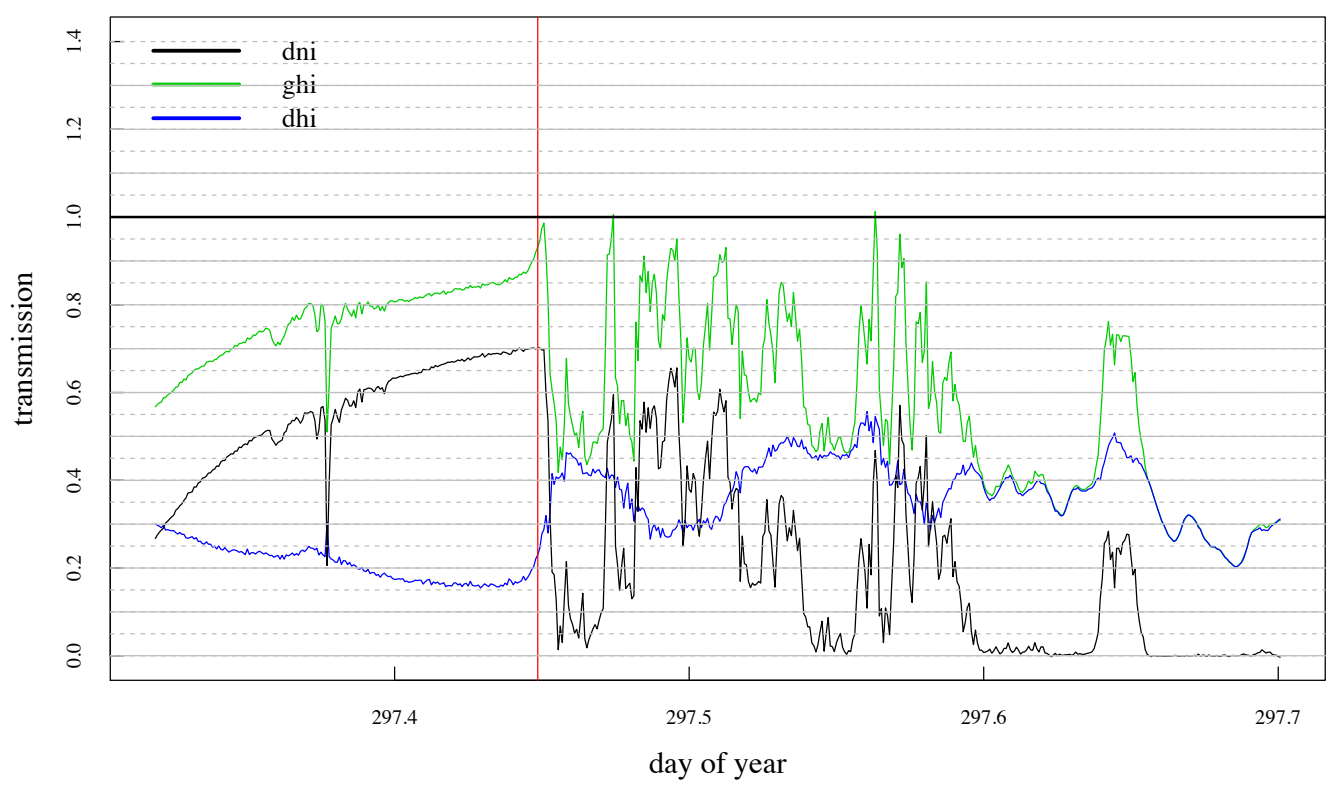

410 Figure 8: Plot of the transmission near $500 \mathbf{~ n m}$ for global and diffuse horizontal and direct normal irradiances for 24 October 2009 at the ARM site in northern Oklahoma. The vertical red line marks the time of the measured spectra in Figure 7. The dni appears unaffected by nearby clouds, but the dhi and, therefore, the ghi are enhanced over the clear-sky values explaining the effect of apparent transmissions greater than $100 \%$ in Figure 7. 
https://doi.org/10.5194/amt-2021-162

Preprint. Discussion started: 23 June 2021

(c) Author(s) 2021. CC BY 4.0 License.

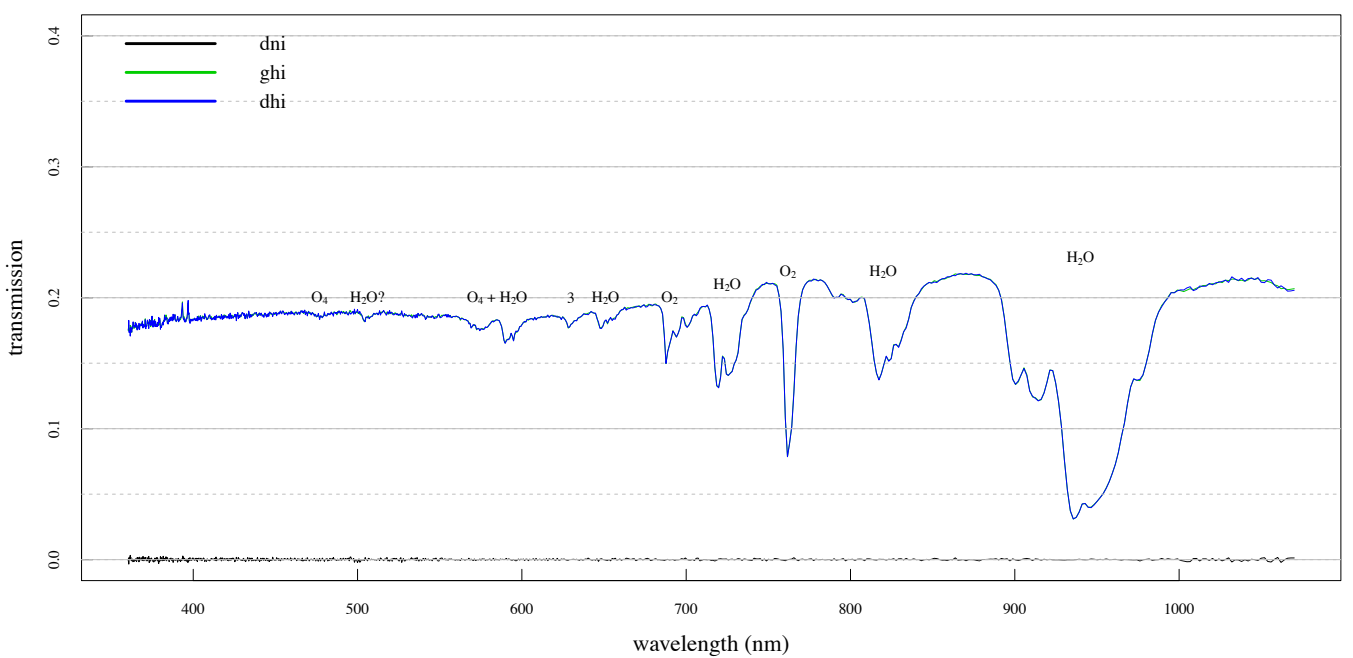

Figure 9: Spectrally continuous transmission spectrum for a totally overcast sky on 25 October 2009 at the northern Oklahoma ARM site. Outside the molecular bands there is an overall monotonic increase in transmission with wavelength. The band identified by the number " 3 " near $630 \mathrm{~nm}$ includes overlapping $\mathrm{H}_{2} \mathrm{O}, \mathrm{O}_{2}$, and $\mathrm{O}_{4}$ bands. The bands labeled $\mathrm{O}_{4}+\mathrm{H}_{2} \mathrm{O}$ are overlapping bands. $\mathrm{H}_{2} \mathrm{O}$ ? is identified as a weak water band in the HITRAN database. 
https://doi.org/10.5194/amt-2021-162

Preprint. Discussion started: 23 June 2021

(c) Author(s) 2021. CC BY 4.0 License.

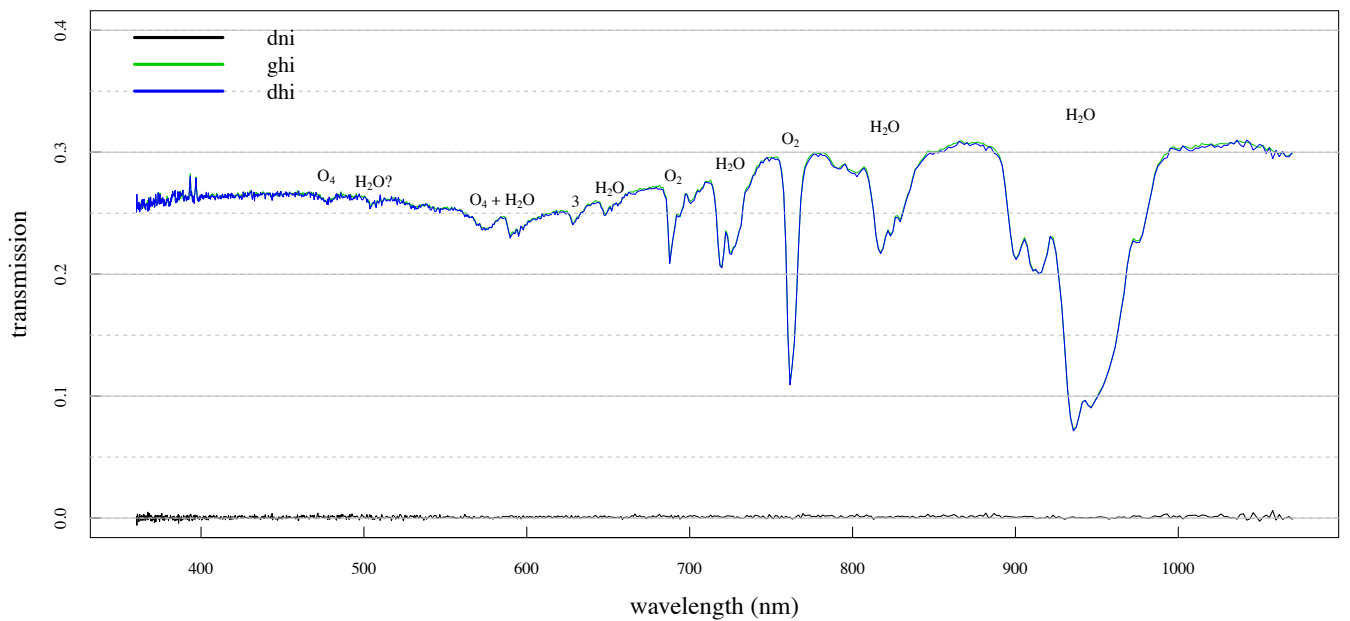

Figure 10: Similar plot to Figure 9, but for overcast skies on 24 October 2009 with higher overall transmission. Note the same details for the absorption features except for the more pronounced Chappuis ozone band centered near $600 \mathrm{~nm}$. See Figure 9 caption for molecular identification details. 
https://doi.org/10.5194/amt-2021-162

Preprint. Discussion started: 23 June 2021

(c) Author(s) 2021. CC BY 4.0 License.

Atmospheric

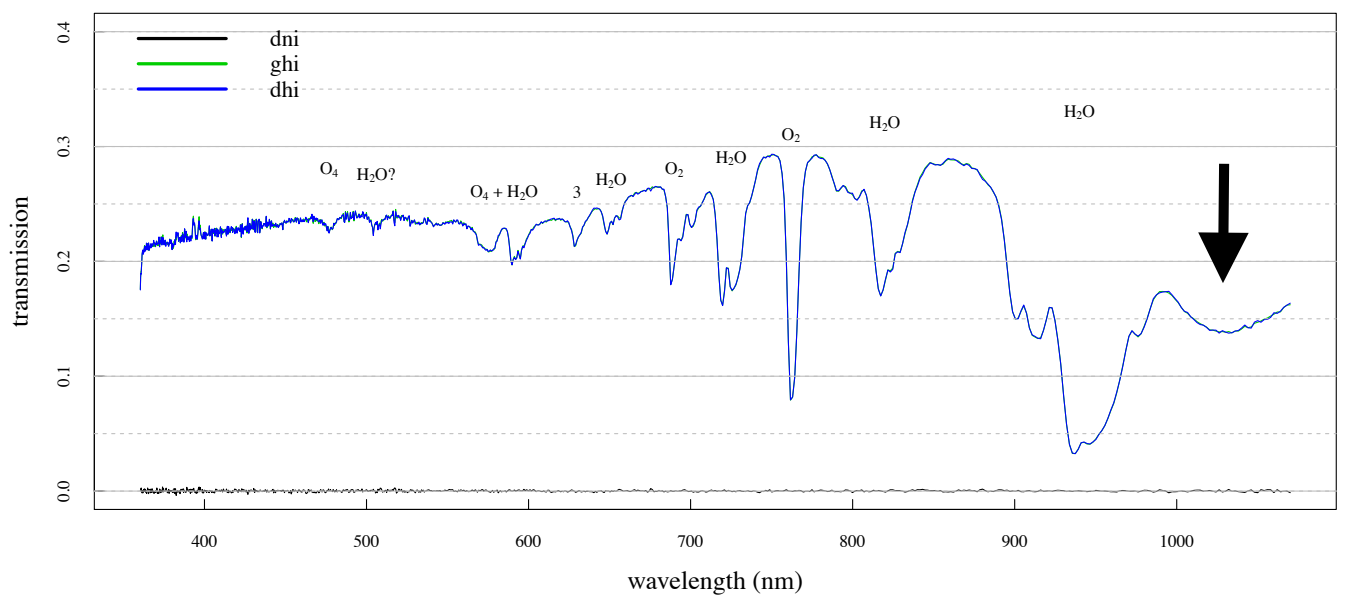

430 Figure 11: Spectral irradiance plot for overcast day 24 December 2009 with ice clouds present as identified from ARM radar measurements. Note the pronounced difference in the spectrum beyond $1000 \mathrm{~nm}$ compared to Figures 9 and 10 indicated by the arrow between 1000 and $1100 \mathrm{~nm}$. 
https://doi.org/10.5194/amt-2021-162

Preprint. Discussion started: 23 June 2021

(c) Author(s) 2021. CC BY 4.0 License.

Aerosol Optical Depth (?) for Midday 25 Novermber 2009

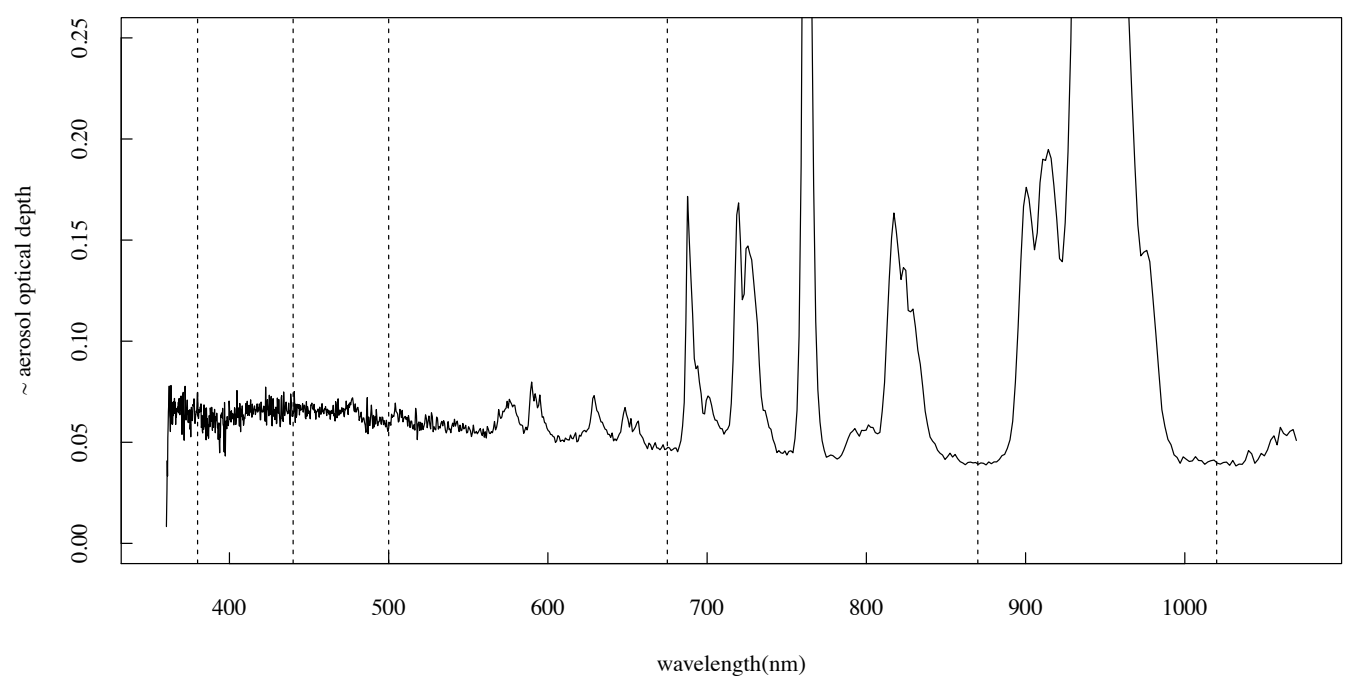

Figure 12: Aerosol optical depth versus wavelength at 11:45 local standard time at the ARM central facility in northern Oklahoma. The vertical lines are drawn at the wavelengths used in the CIMEL sunphotometers employed by AERONET in this wavelength range for measuring AODs. The $\mathrm{O}_{2}$ band at $760 \mathrm{~nm}$ and the $\mathrm{H}_{2} \mathrm{O}$ band at 940 has been truncated at 0.25 optical depth to better see the aerosol wavelength dependence. 
https://doi.org/10.5194/amt-2021-162

Preprint. Discussion started: 23 June 2021

(c) Author(s) 2021. CC BY 4.0 License.

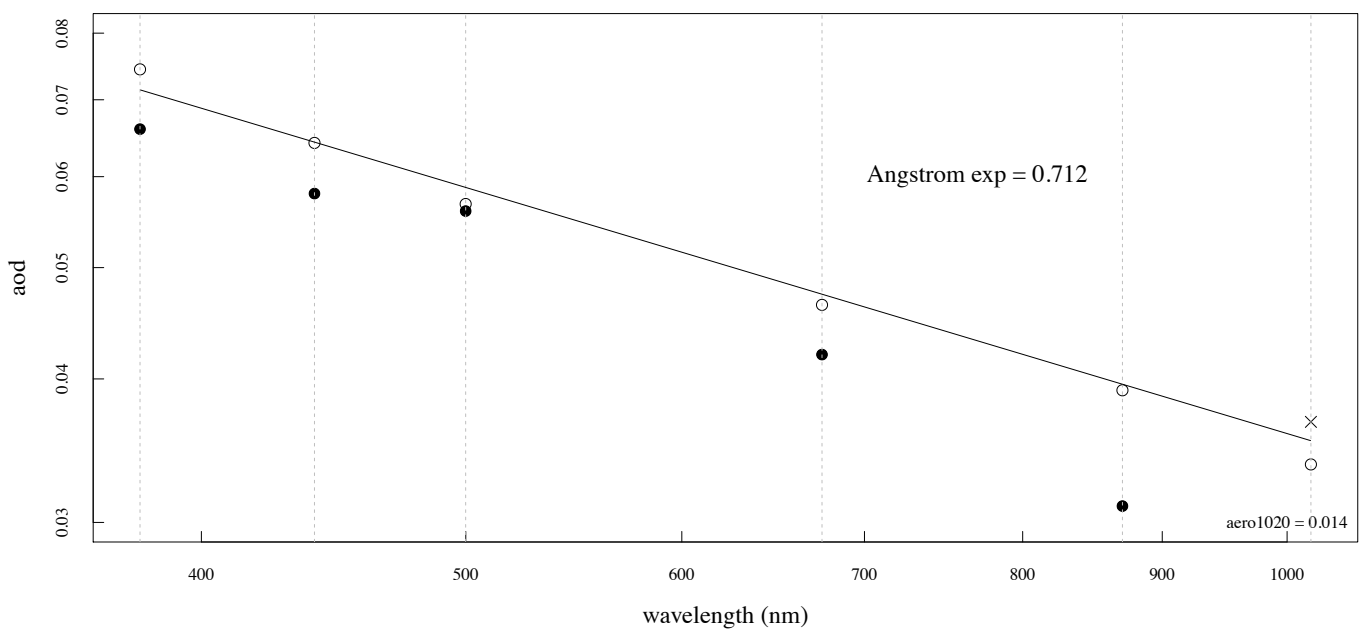

Figure 13: RSS AOD (open circles) versus wavelength for pixels nearest AERONET wavelengths from Figure 12. Least squares fit to the RSS points yields an Angstrom exponent equal to 0.711. The filled circles are the AERONET points taken within 2.5 minutes of the RSS data. Except for 1020 agreement is within 0.008 AOD. 
https://doi.org/10.5194/amt-2021-162

Atmospheric

Preprint. Discussion started: 23 June 2021

(c) Author(s) 2021. CC BY 4.0 License.

Day of Year $=300$

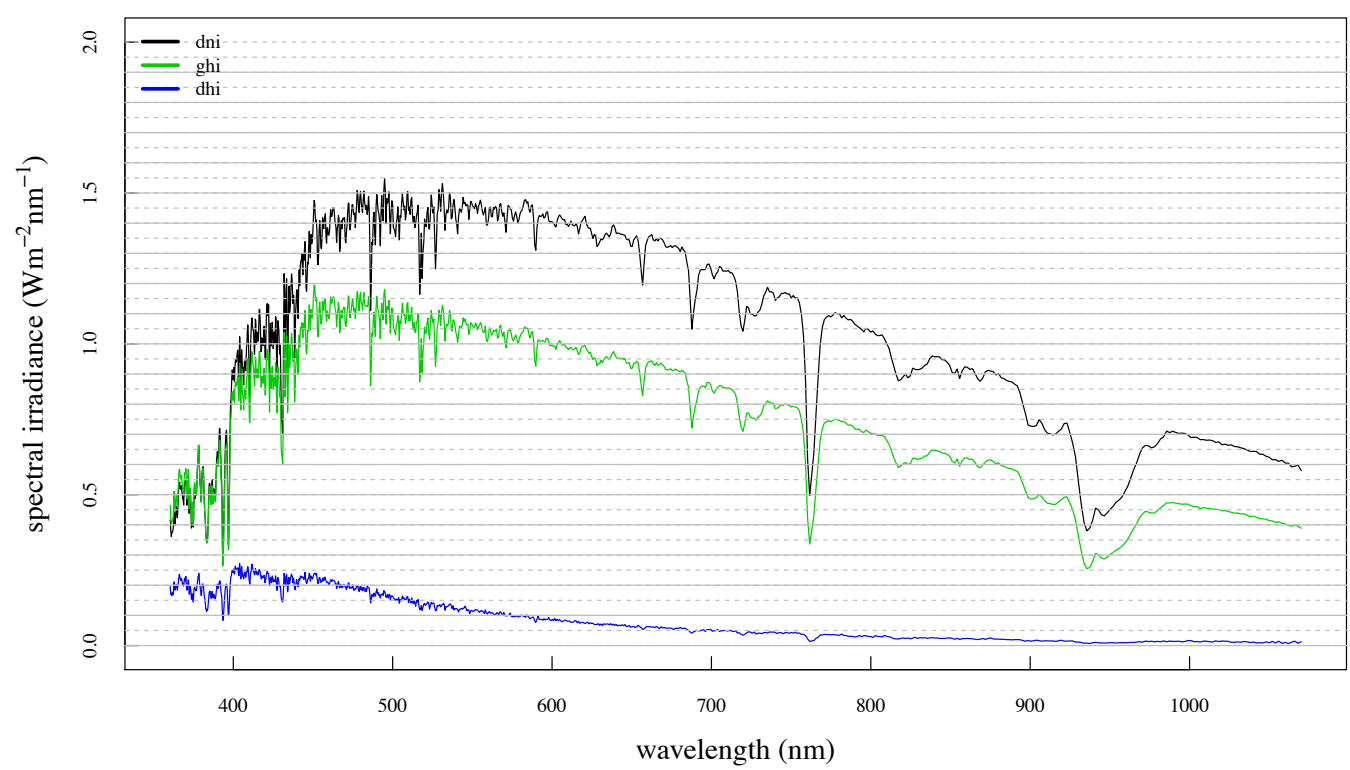

Figure 14: Spectral irradiance calculated using RSS measurements for three solar components near solar noon at the ARM site in northern Oklahoma on 27 October 2009. 